\title{
A Genetic Platform for Functionally Profiling Odorant Receptors Ex Vivo Using Olfactory Cilia.
}

Authors: Masayo Omura ${ }^{1,3 \#}$, Yukie Takabatake ${ }^{1,3 \#}$, Sigi Benjamin-Hong ${ }^{3}$, Charlotte D’Hulst ${ }^{1,3}$ \& Paul Feinstein ${ }^{1,2,3 *}$

\author{
Affiliations: \\ ${ }^{\#}$ Both authors contributed equally \\ ${ }^{1}$ Department of Biological Sciences, Hunter College, City University of New York, New York, \\ NY 10065 \\ ${ }^{2}$ The Graduate Center Programs in Biochemistry, Biology and CUNY Neuroscience \\ Collaborative, 365 5th Ave, New York, NY 10016 \\ ${ }^{3}$ Yesse Technologies, Inc., New York, NY 10016, USA.
}

*Corresponding author. E-mail: Feinstein@genectr.hunter.cuny.edu

\section{One Sentence Summary:}

olfactory-cilia based odor screening platform.

\begin{abstract}
The molecular basis for odor perception in humans remains a black box as odorant receptors (ORs) are notoriously difficult to study outside of their native environment. Efforts toward OR expression and functional profiling in heterologous systems have been met with limited success due to poor efficiency of cell surface expression and consequently reduced Gprotein signal amplification. We previously reported a genetic strategy in mice to increase the number of sensory neurons expressing specific ORs, which transforms the 10 million neurons of the mouse nose into a bioreactor producing large quantities of fully functional OR protein. We now describe the isolation of cilia from these bioreactors for two human ORs. Cilia are known to contain all components of the olfactory signal transduction machinery and can be placed into an ex vivo well-plate assay to rapidly measure robust, reproducible odor-specific responses. Our OR1A1 and OR5AN1 isolated cilia reveal 10-100fold more sensitivity than existing assays. Tissue from a single animal produces up to 4,000 384-well assay wells, and isolated olfactory cilia can be stored frozen and thus preserved for long term usage. This pipeline offers a sensitive, highly scalable ex vivo odor screening platform that opens the door for decoding human olfaction.
\end{abstract}

\section{Introduction}

Decoding the sense of smell has remained elusive for the last 30 years. Odors are recognized by olfactory or odorant receptors (ORs), which are seven transmembrane (7TM) receptors 
belonging to the G-protein Coupled Receptor (GPCR) superfamily. Mice express over 1000 intact OR genes, while the human OR repertoire is composed of $\sim 400$ intact genes (1-3). It has been exceedingly difficult to identify odors that activate ORs and even if an odor can be identified in vitro, one has to validate the observation in vivo, which is rarely done (4-6). What is needed is a manner to produce an OR in an olfactory neuron and rapidly characterize it. Olfactory sensory neurons (OSNs) express a single allele of one OR gene at a time. In mice, this translates to a mere $\sim 0.1 \%$ of the total number of OSNs in the main olfactory epithelium (MOE) expressing the same OR, thereby posing a challenge for measuring the activity from a single OR.

We have been studying how to increase OR gene choice in olfactory neurons (7) and have shown we can dramatically increase the total number of OSNs expressing specific OR coding sequences. We previously reported a genetic approach allowing us to functionally characterize ORs in their native environment, the olfactory neurons within the nose. As such, instead of 10,000 olfactory sensory neurons (OSNs) representing each of the 1000 mouse ORs, we now have at least 500,000 OSNs represented by our OR transgene (7). Additionally, our approach expressing ORs in the mouse olfactory system allows us to determine for the first time whether specific human ORs are fully functional in also providing neuronal and axonal identity.

In the mammalian olfactory system, the entire odor binding capacity of a neuron exists within olfactory cilia, which protrude from the dendritic knobs of the OSNs into the mucus of the MOE lining the nasal cavity. ORs in cilia detect odors through a $\mathrm{G}$ protein-coupled signaling cascade (Fig.1). Upon odorant binding, the GPCR cascade activates type III adenylate cyclase (ACIII), resulting in a rapid rise in the second messenger cyclic AMP (cAMP), which subsequently binds and opens cyclic-nucleotide gated channels to promote calcium influx. The initiation of the odor transduction pathway and its key enzymatic components are exclusively localized to olfactory cilia (8-12). Isolated olfactory cilia contain the full OR signaling protein machinery (13) and can be utilized ex vivo to measure odor-induced OR activation with an adenylyl cyclase assay (14).

While previous studies have used isolated cilia to measure OR activation, this method alone cannot be used to pinpoint the activation of individual ORs in response to odorants. In mice, each OR is represented in at most $0.1 \%$ of all OSNs. Consequently, there are not enough cilia of a single OR type to define receptor-specific response profiles. Odor induced signals generated by all other ORs further complicate measuring signal output from a single OR type.

To circumvent these issues, we are taking a genetic approach to express human ORs in a large fraction of OSNs. To do this, we have generated transgenes that increase the representation of selected ORs by at least 250 -fold (7). We show that this dramatic overrepresentation provides the resolution necessary to identify odor responses unique to the over-represented OR. The expressed OR is easily determined as functional and physiologically relevant by examining the formation of green fluorescent glomeruli. A fundamental advantage of cilia isolation for ex vivo analysis over heterologous expression systems is they can be aliquoted and stored for prolonged periods of time (15-17). These cilia originate in transgenic animals that highly express the OR of interest. This is a clear advantage over heterologous systems that don't include native binding and accessory factors in the membrane which are significant for proper OR signaling.

Furthermore, we show that a green fluorescent sensor such as GCaMP6f $(13,18)$ can be targeted to olfactory cilia in transgenic lines, leaving open the possibility of measuring odor signaling optically within cilia $(19,20)$. 
Our platform can generate an OR of our choosing to be expressed in a large number of OSNs such that cilia can be isolated and characterized with odors or ligands in a quick bench-top bioassay. The data reveal robust and reproducible nanomolar responses in liquid phase delivery of odorants. Vapor phase activation of ORs shows equivalent activation profiles as liquid delivery. OR activation is sensitive, specific and selective in a concentration dependent manner. This cilia-based platform finally opens a door for odor characterization of ORs including the entire repertoire of human ORs.

\section{Results}

\section{Expression of Human Odorant Receptors}

In order to functionally characterize ORs in cilia, we developed a strategy to 1) increase the number of OSNs expressing a given OR, and 2) isolate cilia for functional analysis.

To develop our approach, we employed two well-characterized human ORs: OR1A1 and OR5AN1 (21-26). Our platform uses a transgene that has three modules that can be readily modified: 1) the 5 'end where either five or nine repeats of a gene choice enhancer (x21) are used to boost the representation of a specific OR; 2) the CDS, where any OR CDS can be inserted; and 3) a bicistronic reporter (IRES-Reporter) inserted 3' of the CDS (Fig.1). To label all membranes in an OSN including cilia, we fused a previously characterized membrane targeting peptide tag (Myristylation/Palmitoylation) to the green fluorescent reporter GCamp6f (20). We generated two transgenic constructs: OR1A1-IRES-MyrPalm-GCaMP6f mice (OR1A1) and OR5AN1-IRES-MyrPalm-GCaMP6f mice (OR5AN1), both driven using a 9x21 enhancer. In 2/2 OR5AN1 and 1/1 OR1A1 transgenic mouse lines, we observe many more OSNs expressing the transgene in wholemount analysis of the epithelium and glomerular projections than a genetargeted OR. In addition, MyrPalm-GCaMP6f robustly labels membranes of axons as they project to the olfactory bulbs and form large glomeruli (Fig.2). Moreover, en face images of olfactory epithelium reveals brightly fluorescent labeled ciliary membranes (Fig.2) consistent with the MyrPalm lipid modification.

\section{Functional Activation of ORs in from rapidly Extracted Olfactory Cilia}

Odorant receptor signaling is self-contained in the cilia where ORs, Golf, ACIII and CNG2A are localized. To study OR response profiles, we developed a pipeline to isolate cilia (15-17) and measure specific odor activation ex vivo. Cilia preparations were taken from transgenic and control mice using modified deciliation protocols $(15-17,26)$. We confirmed that Golf and ACIII were in our isolated cilia preps by Western blotting (not shown). It has previously been described that isolated cilia can readily convert ATP into cAMP in an odor dependent manner (Fig.1). To detect OR activation to odorants in our human OR isolated cilia (hOR bioextracts), we utilized a modified adenylyl cyclase assay (15) combined with a commercially available cAMP kit to measure accumulated cAMP levels in isolated olfactory cilia. Isolated cilia from a single mouse were placed in $10 \times 5 \mu l$ aliquots and frozen. Each odor activation experiment 
requires a minimum of 0.0125 ul per well of a 384-well plate, yielding up to 400 reactions per 5 $\mu 1$ aliquot.

To test for receptor-specific responses, we compared cAMP responses in cilia from transgenic and non-transgenic control preparations using known OR1A1 and OR5AN1 agonists. To normalize for variability across ciliary preparations, we initially measured the maximum cAMP response in each preparation using the adenylate cyclase activator forskolin (FSK). Baseline cAMP production with DMSO or ethanol solvents range at 0.01-0.03 $\mu \mathrm{M}$ cAMP. By contrast FSK activation yielded $\sim 10$-fold higher levels $(9.95 \pm 0.81-10.61 \pm 0.66)$ of cAMP between 0.05 and $0.38 \mu \mathrm{M}$ (Fig.3A). We noted a strong correlation between the baseline levels of cAMP compared to the FSK-activated cAMP $\left(\mathrm{R}^{2}=0.953\right.$, Fig. $\left.1 \mathrm{~B}\right)$. Thus, the baseline value of cAMP was used to normalize across experiments.

We tested for ligand response selectivity of OR5AN1 and OR1A1 to their reported ligands (5 $\mu \mathrm{M}$ muscone for OR5AN1 and $50 \mu \mathrm{M}$ MND, 3-methyl-2,4-nonanedione, for OR1A1). OR5AN1 demonstrated a significant response to its published ligand muscone (25) at $5 \mu \mathrm{M}$ (Activation $(\mathrm{A})=9.41 \pm 1.31 \mathrm{SEM})$ (Fig.3C, left) compared to non-transgenic wild-type (WT) cilia (A= $1.0 \pm 0.30)$. Similarly, OR1A1 responded to its published ligand MND (21) at $50 \mu \mathrm{M}(\mathrm{A}=5.72$ \pm 0.82 ) (Fig.3C, right) compared to WT cilia.

We further characterized OR5AN1 using a panel of 12 hedonically similar musk compounds of various chemical structures (Fig.S1). In agreement with recent reports $(22,23,25$, 27), OR5AN1 selectively responds to macrocyclic (compounds M1-M7), polycyclic (compound P1), and nitro musks (compounds N1-2) by demonstrating low micromolar to nanomolar sensitivity while showing a complete lack of response to alicyclic (compound A1-A2) musks (Fig.4. S2 and S3). We demonstrate that the assay can discern affinity for various compounds based on 1) response intensity: the magnitude of the response to musks, and 2) response sensitivity: presence of response after serial dilutions of compounds.

We sought to define dose-response curves. However, high concentrations ( $\geq 5 \mu \mathrm{M})$ of certain musks had a deleterious effect on cAMP production, even in WT cilia (Fig.S2). This suggests interference with cAMP production perhaps from introducing high concentrations of hydrophobic compounds in the ciliary membrane. Notably, we observe activation to drop below 1 when administering higher concentrations, preventing a simple calculation of EC50s. Despite this drawback, we were still able to observe clear differential response to musks previously reported as weak or non-ligands of OR5AN1, ambrettolide (M3), ethylene brassylate (M4), habanolide (M5), and galaxolide (P1). Moreover, we controlled for the reduction in response by normalizing responses, taking the (Odor induced cAMP-DMSO)/DMSO values (Fig.S2) and shifted all WT and corresponding Tg values to 1.0. (Fig.4). We find that musk tibetene has the lowest EC50 at $-7.482 \mathrm{M}$, but not the strongest activation at only 16.3 at $-5.801 \mathrm{M}$ (Fig.4). By contrast, musk ketone and muscenone have slightly low EC50s at $-6.750 \mathrm{M}$ and $-6.583 \mathrm{M}$, 
respectively, while having activations as much as about 30-fold over WT at distinct concentrations.

\section{Selectivity, Specificity, Sensitivity, Intensity, Reproducibility and Repeatability of OR responses}

Given that odors normally enter the nose as volatile compounds present in the headspace, we next tested whether our ex vivo odor bioassay would be amenable to vapor phase delivery. To perform this series of experiments, we built a benchtop olfactometer with a custom Teflon manifold allowing delivery of up to 6 individual odors to 16 different cilia preps on a 96-well plate. We have observed little to no crosstalk from neighboring odor line chambers ( Fig.S4) and can modulate concentration of delivered headspace by air dilution (Fig.S4). Delivery of headspace saturated with (-)-carvone (Saturated Vapor Pressure, SVP: $23.5 \mu \mathrm{M}$ ) elicited a response from the OR1A1 sample that was significantly above either WT or OR5AN1 responses (Fig.5A). Similarly, muscenone (SVP: $5.92 \mu \mathrm{M}$ ) differentially stimulated OR5AN1 compared to either WT or OR1A1 (Fig.5B). We observed that the odor delivery of compounds by vapor phase (Fig.5) is comparable to that of the liquid phase at the equivalent concentrations (Figure 4).

MND, 3-methyl-2,4-nonanedione, is the highest affinity odor for OR1A1; two lower affinity ligands are the stereoisomers (-)-carvone and $(+)$-carvone $(21,24)$. We tested if the OR1A1 cilia would distinguish these stereoisomers. These lower affinity ligands showed differential responses in the 9x21-OR1A1-Gcamp6f cilia with (-)-carvone eliciting greater activation than $(+)$-carvone. However, the data were more easily quantified using our 5x21-OR1A1-Cherry line (7) with higher representations, where MND provided activation over WT cilia in the 50-150 fold range (Fig.S5) depending on the cilia preparation. Raw cAMP production values were always higher for MND followed by (-)-carvone and lastly (+)-carvone (Fig.S5). If we normalize the fold activation for these three odors and take the average of 6 independent measures, MND is responding 3x over (-)-carvone, which in turn is responding 5x over $(+)-$ carvone (Fig.6).

\section{Discussion}

\section{Heterologous expression systems}

Heterologous expression systems have provided a wealth of pharmacological profiling for hundreds of GPCRs and the development of novel agonists and antagonists. These nonchemosensory GPCRs are typically characterized by robust plasma membrane expression in heterologous systems (28). However, nasal chemosensory GPCRs (Class I and II ORs as well as vomeronasal receptors) have exhibited poor plasma membrane expression in heterologous systems no matter the organism of origin (29). 


\section{ORs are difficult to express in heterologous cells}

It is estimated that only $10 \%$ have one identified ligand among the $\sim 400$ intact human odorant receptors (30). Heterologous OR expression systems would lend themselves for highthroughput ligand characterization, but 30 years of effort has failed to decode how humans identify odors. To date, we still don't understand why expression of the unmodified OR protein does not traffic to the plasma membrane outside of the olfactory neuron (31). Class A GPCRs do not have a signal peptide, but rather use the first transmembrane domain as a "signal domain" for insertion into the plasma membrane. In an effort to force plasma membrane expression in heterologous systems, many laboratories have added signal peptides to the amino-termini of these 7TM proteins or made chimeric GPCRs whereby the first and last transmembrane domains belong to non-chemosensory GPCRs (32). These modifications could disrupt the true odor profile of an OR. A promising line of research identified the putative GPCR cilia trafficking cofactors RTP1 and REEP1 based on functional screens looking for single pass proteins like odr-4. A third cofactor Ric $8 b$ was found in a similar manner (33). But, using both amino terminal tagging of ORs and cofactors, still produces very little protein on the plasma membrane compared to two canonical GPCRs beta2 adrenergic receptor or rhodopsin (34).

\section{Advantages of functional expression of cilia}

Our approach obviates difficulties with heterologous expression by expressing ORs in native OSNs. This allows for proper OR localization to cilia plasma membrane as well as the natural environment for G-protein coupling. We show that comparing responses in WT cilia vs responses in cilia from transgenic overexpressing mice allows us to quantify odorant response properties of specific human ORs. Indeed, our calculated activation revealed odor-OR activities at nanomolar concentrations for high affinity ligands. The sensitivity of OR5AN1 for muscone is 40-100fold better than other assays with our EC50 at 0.29uM (Figure 4) compared to 12.5-32.1 $\mathrm{uM}(22,25)$. Our OR1A1-Cherry mice with many more cells than the OR1A1-Gcamp6f mice, has a threshold of sensitivity to MND in the low $\mathrm{nM}$ range compared to best published responses in the 100nM range. Moreover, our assay can be used with any OR, even those that are resistant to functional expression in heterologous cells.

Another advantage of our assay is that it allows us to evaluate all required functions of ORs. In addition to binding odorants, ORs promote neuronal maturation and are required for proper axon guidance. Thus, for an OR to be used for ligand/odor detection, it must retain all three functions (35). In this context, if a full-length OR fails to do so, then we would consider it an intact pseudogene or non-functional gene. It is difficult to examine all three OR functions in humans. In fact, single cell sequencing of human OSNs has revealed around 140 out of 400 ORs with high levels of expression suggesting that their neurons have matured. Our assay provides a method to determine full functionality of human ORs by expressing them under OR gene choice control mechanisms and assessing stable glomerular formation, as we have done for OR1A1 and OR5AN1. In this view, human ORs have not been fully characterized until their ability to support OSNs maturation and glomerular formation has been assessed.

Our approach is also scalable. Our highly represented ORs in mice provide enough material for maximum 4000 assays from one mouse to produce signals that are at least 3-fold over nontransgenic (wildtype, WT) signals when using a high affinity ligand. We show signals up to 100fold over WT when a very high affinity ligand is identified. 


\section{Odorant receptors versus chemical detection devices}

Analytical chemistry characterizes chemicals by a subset of its features (light interaction, heat interaction, electric or magnetic field interactions). Olfaction is a measure of complex intermolecular forces (hydrogen or ionic bonding, ion-dipole or ion-induced dipole forces, van der Waals forces) between a chemical and a protein such that these intermolecular forces (ligand binding) have been optimized over evolutionary time to produce high affinity states that GPCR systems translate into intracellular signals in seconds (36). One ligand molecule can lead to the activity of hundreds of G-proteins each capable of stimulating adenylate cyclase activity leading to large numbers of cAMP molecules. The strength of GPCR activation as we show provides differential responses over a 2-log range and saturate over another 2-3 log range $(37,38)$. Taken together, ORs provide the signal amplification, specificity, intensity that dwarfs any non-specific chemical detection device.

\section{Future directions for the platform}

Our cilia preparations from the dorsal recess of the olfactory epithelium are not purely derived from one type of OR. Thus, the more Tg-OR derived cilia in a preparation, the more signal will be obtained as we see when comparing our Tg for 5x21-OR1A1-Cherry to 9x21-OR1A1Gcamp6f; We see 10fold differences in signals (Fig.3C vs. Fig.S6). We recently characterized $5 \times 21-O R 1 A 1-C h e r r y ~(39)$ that reveals the dorsal epithelium is now expressing OR1A1 in $50 \%$ of the OSNs. Further increasing expression in the dorsal epithelium to $100 \%$ of the OSNs may double the signal. In such an animal, nearly all cilia (20-35 cilia/neuron x millions of OSNs) (40) would be provide a rich source of tissue dedicated to deorphanize that one OR at multiple concentrations with many odors. We are currently characterizing several sites in the genome that will express the OR in 50-95\% of all dorsal neurons that can offer a streamlined and standardized method to define ligands for all human odorant receptors.

\section{Volatile Odors Emitted by Parkinson's Disease:}

In addition to characterizing responses of all human ORs to decode olfaction, our approach can be used to characterize odors emitted by skin or urine, e.g. Comparing the odor profiles of healthy individual over time may reveal odors indicative of a disease state. The use of ORs is different from a general chemical detection platform because it will distill out chemicals or odortopes that are high affinity and have been evolutionarily selected to identify signal from the noise in a complex odor mixture. Recently GCMS has been used to identify volatile odors emitted by Parkinson's Disease (PD) (41). This analysis was born from the surprising observation that a woman, Joy Milne, who happens to be a supersmeller, was able to notice a distinctive "smell" in her husband over a decade before he was diagnosed with Parkinson's Disease. We envision that a platform with many ORs could distinguish Pre-Parkinson's Disease odor states from healthy subjects. 


\section{Materials and Methods}

\section{Materials}

Musk compounds were an in-kind contribution from Givaudan. Muscone, (-)-carvone, and (+)carvone were purchased from Sigma Aldrich. 3-methyl-2,4-nonanedione was purchased from Santa Cruz.

\section{Generation of Transgenic Animals}

The targeting vector of 5x21-OR-IRES-MyrPalm GCaMP6f generated by swapping IREStaumCherry sequences with IRES-MyrPalm GCaMP6f with PacI site. the 5x21 enhancer sequence was modified to $9 \times 21$ to generate the final targeting vector 9x21-OR1A1-IRESMyrPalm GCaMP6f. To generate with other OR genes, A StuI-AscI fragment which is 187 bases of intron of M71 attached to full CDS of OR1A1 gene was replaced with the StuI-AscI fragment with target OR gene CDS (Integrated DNA technologies). Linearized targeting vectors were purified used for pronucleus injection to obtain founders animals. Founders were bred with CD1 mice. The transgenic animals were maintained by PCR screening. Mice used in this study were bred and maintained in the Laboratory Animal Facility of Hunter College, CUNY. The Hunter College IACUC approved all procedures. Animal care and procedures were in accordance with the Guide for the Care and Use of Laboratory Animals (NHHS Publication No. [NIH] 85-23).

\section{Characterization of Animals}

4 to 12 weeks old mice were used for the analysis by wholemount confocal microscopy imaging with LSM510 (Zeiss). For en face imaging of the GCaMP positive cells, the dorsal region of the olfactory epithelium was peeled and placed on a slide glass and sealed with live imaging solution (Invitrogen), and coverslipped. Images were taken with UltraView ERS spinning disk confocal microscope (Perkin Elmer). The images were analyzed with Fiji.

\section{Deciliation of Olfactory Sensory Neurons}

Deciliation of OSN was performed with modifications to a previously published protocol (16). Briefly, olfactory epithelium (dorsal recess) from 6-10 week old mice were dissected and placed in ice-cold buffer $\mathrm{A}\left(145 \mathrm{mM} \mathrm{NaCl}, 1.6 \mathrm{mM} \mathrm{KCl}, 1.6 \mathrm{mM} \mathrm{K}_{2} \mathrm{HPO}_{4}, 1.2 \mathrm{mM} \mathrm{MgSO}_{4}, 25 \mathrm{mM}\right.$ HEPES, 7.4 mM D-Glucose, cOmplete ${ }^{\mathrm{TM}}$ Protease Inhibitor cocktail, $\mathrm{pH} 7.4$ ) then exchanged for ice-cold buffer B (cold buffer A supplemented with $1 \mathrm{mM}$ EDTA, pH7.4) and rocked at $4^{\circ} \mathrm{C}$ for 15 minutes. The sample is sonicated at low power at $4^{\circ} \mathrm{C}$ twice, then spun down in a centrifuge at low speed for 10 minutes and the supernatant collected in a pre-chilled microcentrifuge tube. The supernatant is spun down at higher speed at $4^{\circ} \mathrm{C}$ for 15 minutes. The resulting pellet is washed once in cold TEM buffer (10 mM Tris, $1 \mathrm{mM}$ EDTA, $3 \mathrm{mM} \mathrm{MgCl}$, $\mathrm{pH} 8.0$ ), then spun down at higher speed again for 15 minutes. The pellet is resuspended in a small volume of TEM buffer with or without $10 \%$ glycerol and aliquoted into working volumes for subsequent assays. Aliquots are flash-frozen in liquid nitrogen and stored at $-80^{\circ} \mathrm{C}$ until use. 


\section{Ex Vivo Bioassay}

Isolated cilia from the dorsal recess are diluted in cold Induction Buffer (25 mM HEPES, $5 \mathrm{mM}$ $\mathrm{MgCl}_{2}, 1 \mathrm{mM}$ ATP, $20 \mu \mathrm{M}$ GTP, $10 \mathrm{nM} \mathrm{GDP}, 1 \mathrm{mM}$ DTT) at a dilution of 1:200 from the original TEM $+10 \%$ glycerol or without glycerol stock. For liquid delivery of odor, ligands are dissolved in DMSO or ethanol as an intermediate solvent between $50 \mathrm{mM}$ and $1 \mathrm{M}$. Diluted isolated cilia are exposed to ligands pre-dissolved in Induction Buffer for 20 minutes at $37^{\circ} \mathrm{C}$. For headspace delivery of odor, ligands are either delivered pure or diluted with dipropylene glycol and placed in an amber vial connected to a custom olfactometer. Odor volume in the vial is set at $100 \mu \mathrm{L}-500 \mu \mathrm{L}$, and the dilution is dependent on the calculated saturated vapor pressure delivery amount for a 20 minute odor delivery. Odors delivered pass through a custom 96-well manifold that fits a well plate containing diluted cilia, in which the well plate is heated from below at $37^{\circ} \mathrm{C}$. Following this incubation, cAMP is measured using the PerkinElmer AlphaScreen cAMP immunoassay (Cat\#6760635) according to manufacturer's recommendation. The activation of the bioextract of hOR expressing transgenic mice was evaluated by three different calculations. A) activity of each sample by ligands of Tg and WT was calculated by produced cAMP responding to ligand and DMSO: (Ligand-DMSO)/DMSO (Fig.S2), B) to evaluate the activation of bioextract of transgenic relative to its wild type, the fold activation value (Tg/WT) was calculated as activation value of transgenic divided by the absolute value of mean of its WT since some ligand gave negative effect on cAMP production. If the value of WT was -1 , all adjusted to 1 by adding 2, [Ligand-DMSO)/DMSO] $]^{\mathrm{Tg}} /$ mean of [Ligand-

DMSO)/DMSO] ${ }^{\text {WT }}$ (Fig.3C, Fig.5, Fig.S3). C) to evaluate the odors give a negative effect on cAMP production (like Musk compounds), the normalized activity of each sample (values of A) was corrected with the mean value of it WT to 1.0: [(Ligand-DMSO)/DMSO $]^{\mathrm{TG}}+1-($ mean of [(Ligand-DMSO)/DMSO ${ }^{\mathrm{WT}}$ )(Fig.4). 3 technical replicates and a minimum of 3-5 biological replicates.

\section{S3I and R2 Analysis}

Activation of a specific OR is calculated by the Activation values, which represents the differential fold change of odor stimulation over solvent stimulation at an endpoint measurement. A successful response is defined as a significant $(\mathrm{p}<0.05)$ increase in response of the bioextracts expressing a specific OR when compared to a non-transgenic control sample. We have defined 6 parameters to measure successful profiling of a specific OR (or set of ORs) with a given ligand (or mixture of ligands): Sensitivity, Selectivity, Specificity and Intensity (S3I) and Repeatability and Reproducibility $\left(\mathrm{R}^{2}\right)$. All 6 parameters can be measured using our existing ex vivo bioassay:

- Selectivity: The selected human OR bioextract ( $\mathrm{n}=3$ biological replicates) is stimulated with compounds. A negative control, which non-specifically stimulates the OR, and a positive control, a known ligand specific to the OR, is used in tandem as a benchmark for OR activation. Compounds that generate a response (activation value) significantly higher than the negative control $(\mathrm{p}<0.05)$ are determined as selective against the human OR. 
- Specificity: Ligand response will be compared among wildtype (non-transgenic) and ORs ( $n=3$ biological replicates). A ligand is identified as specific to the OR if the OR differentially responds to the ligand compared to WT or any other OR.

- Sensitivity: The specific human OR responds at the lowest concentration to the tested ligand. The ligand that evokes a response at the lowest concentration sets the threshold for the OR and is then identified as the highest-affinity ligand.

- Intensity: A dose-response curve for 4-5 odor concentrations shows a concentrationspecific activation profile of the human OR.

- Repeatability and Reproducibility: To obtain statistically relevant data, all experiments will be carried out by using 3-5 biological (different animal, same OR) and 3-4 technical (same animal, same OR) replicates per OR and odor concentration.

\section{References and Notes:}

1. Olender T, Lancet D, Nebert DW. Update on the olfactory receptor (OR) gene superfamily. Hum Genomics. 2008;3(1):87. doi: 10.1186/1479-7364-3-1-87 PMID - 19129093.

2. Marenco L, Wang R, McDougal R, Olender T, Twik M, Bruford E, Liu X, Zhang J, Lancet D, Shepherd G, Crasto C. ORDB, HORDE, ODORactor and other on-line knowledge resources of olfactory receptor-odorant interactions. Database (Oxford). 2016;2016. Epub 2016/10/04. doi: 10.1093/database/baw132. PubMed PMID: 27694208 ; PMCID: PMC5045865.

3. Olender T, Keydar I, Pinto JM, Tatarskyy P, Alkelai A, Chien MS, Fishilevich S, Restrepo D, Matsunami H, Gilad Y, Lancet D. The human olfactory transcriptome. BMC Genomics. 2016;17(1):619. Epub 2016/08/16. doi: 10.1186/s12864-016-2960-3. PubMed PMID: 27515280; PMCID: PMC4982115.

4. Oka Y, Katada S, Omura M, Suwa M, Yoshihara Y, Touhara K. Odorant receptor map in the mouse olfactory bulb: in vivo sensitivity and specificity of receptor-defined glomeruli. Neuron. 2006;52(5):857-69. Epub 2006/12/06. doi: 10.1016/j.neuron.2006.10.019. PubMed PMID: 17145506.

5. Dewan A, Cichy A, Zhang J, Miguel K, Feinstein P, Rinberg D, Bozza T. Single olfactory receptors set odor detection thresholds. Nat Commun. 2018;9(1):2887. Epub 2018/07/25. doi: 10.1038/s41467-018-05129-0. PubMed PMID: 30038239; PMCID: PMC6056506.

6. Zhang J, Pacifico R, Cawley D, Feinstein P, Bozza T. Ultrasensitive detection of amines by a trace amineassociated receptor. J Neurosci. 2013;33(7):3228-39. Epub 2013/02/15. doi: 10.1523/JNEUROSCI.4299-12.2013. PubMed PMID: 23407976; PMCID: PMC3711460.

7. D'Hulst C, Mina RB, Gershon Z, Jamet S, Cerullo A, Tomoiaga D, Bai L, Belluscio L, Rogers ME, Sirotin Y, Feinstein P. MouSensor: A Versatile Genetic Platform to Create Super Sniffer Mice for Studying Human Odor Coding. Cell Rep. 2016;16(4):1115-25. Epub 2016/07/12. doi: 10.1016/j.celrep.2016.06.047. PubMed PMID: 27396335.

8. Schild D, Restrepo D. Transduction Mechanisms in Vertebrate Olfactory Receptor Cells. Physiol Rev. 1998;78(2):429-66. doi: 10.1152/physrev.1998.78.2.429 PMID - 9562035.

9. Jones DT, Reed RR. Golf: an olfactory neuron specific-G protein involved in odorant signal transduction. Science. 1989;244(4906):790-5. Epub 1989/05/19. doi: 10.1126/science.2499043. PubMed PMID: 2499043.

10. Bakalyar HA, Reed RR. The second messenger cascade in olfactory receptor neurons. Curr Opin Neurobiol. 1991;1(2):204-8. Epub 1991/08/01. doi: 10.1016/0959-4388(91)90079-m. PubMed PMID: 1668220.

11. Bakalyar HA, Reed RR. Identification of a specialized adenylyl cyclase that may mediate odorant detection. Science. 1990;250(4986):1403-6. Epub 1990/12/07. doi: 10.1126/science.2255909. PubMed PMID: 2255909.

12. Dhallan RS, Yau KW, Schrader KA, Reed RR. Primary structure and functional expression of a cyclic nucleotide-activated channel from olfactory neurons. Nature. 1990;347(6289):184-7. Epub 1990/09/13. doi: 10.1038/347184a0. PubMed PMID: 1697649. 
13. Delling M, DeCaen PG, Doerner JF, Febvay S, Clapham DE. Primary cilia are specialized calcium signalling organelles. Nature. 2013;504(7479):311-4. doi: 10.1038/nature12833 PMID - 24336288.

14. Shirley SG, Robinson CJ, Dickinson K, Aujla R, Dodd GH. Olfactory adenylate cyclase of the rat Stimulation by odorants and inhibition by Ca2+. Biochem J. 1986;240(2):605-7. doi: 10.1042/bj2400605 PMID 3814101.

15. Sklar PB, Anholt RRH, Snyder SH. The Odorant-sensitive Adenylate Cyclase of Olfactory Receptor Cells. J Biological Chem. 1986;261(33):15538-43.

16. Washburn KB, Turner TJ, Talamo BR. Comparison of mechanical agitation and calcium shock methods for preparation of a membrane fraction enriched in olfactory cilia. Chemical Senses. 2002. doi: https://doi.org/10.1093/chemse/27.7.635.

17. Anholt RRH, Aebi U, Snyder S. A Partially Purified Preparation of Isolated Chemosensory Cilia from the Olfactory Epithelium of the Bullfrog, Rana catesbeiana. The Journal of Neuroscience. 1986. doi:

10.1523/jneurosci.06-07-01962.1986.

18. Chen T-W, Wardill TJ, Sun Y, Pulver SR, Renninger SL, Baohan A, Schreiter ER, Kerr RA, Orger MB, Jayaraman V, Looger LL, Svoboda K, Kim DS. Ultrasensitive fluorescent proteins for imaging neuronal activity. Nature. 2013;499(7458):295-300. doi: 10.1038/nature12354 PMID - 23868258.

19. Delling M, Indzhykulian AA, Liu X, Li Y, Xie T, Corey DP, Clapham DE. Primary cilia are not calciumresponsive mechanosensors. Nature. 2016;531(7596):656-60. doi: 10.1038/nature17426 PMID - 27007841. 20. Uytingco CR, Williams CL, Xie C, Shively DT, Green WW, Ukhanov K, Zhang L, Nishimura DY, Sheffield VC, Martens JR. BBS4 is required for intraflagellar transport coordination and basal body number in mammalian olfactory cilia. J Cell Sci. 2019;132(5). Epub 2019/01/23. doi: 10.1242/jcs.222331. PubMed PMID: 30665891; PMCID: PMC6432715.

21. Geithe C, Noe F, Kreissl J, Krautwurst D. The Broadly Tuned Odorant Receptor OR1A1 is Highly Selective for 3-Methyl-2,4-nonanedione, a Key Food Odorant in Aged Wines, Tea, and Other Foods. Chemical Senses. 2016;42(3):181-93. doi: 10.1093/chemse/bjw117.

22. Sato-Akuhara N, Horio N, Kato-Namba A, Yoshikawa K, Niimura Y, Ihara S, Shirasu M, Touhara K. Ligand Specificity and Evolution of Mammalian Musk Odor Receptors: Effect of Single Receptor Deletion on Odor Detection. Journal of Neuroscience. 2016;36(16):4482-91. doi: 10.1523/jneurosci.3259-15.2016 PMID - 27098692. 23. Ahmed L, Zhang Y, Block E, Buehl M, Corr MJ, Cormanich RA, Gundala S, Matsunami H, O'Hagan D, Ozbil M, Pan Y, Sekharan S, Ten N, Wang M, Yang M, Zhang Q, Zhang R, Batista VS, Zhuang H. Molecular mechanism of activation of human musk receptors OR5AN1 and OR1A1 by (R)-muscone and diverse other musksmelling compounds. P Natl Acad Sci Usa. 2018;115(17):E3950-E8. doi: 10.1073/pnas.1713026115 PMID 29632183.

24. Geithe C, Protze J, Kreuchwig F, Krause G, Krautwurst D. Structural determinants of a conserved enantiomer-selective carvone binding pocket in the human odorant receptor OR1A1. Cell Mol Life Sci. 2017;74(22):4209-29. Epub 2017/06/29. doi: 10.1007/s00018-017-2576-z. PubMed PMID: 28656349.

25. Shirasu M, Yoshikawa K, Takai Y, Nakashima A, Takeuchi H, Sakano H, Touhara K. Olfactory receptor and neural pathway responsible for highly selective sensing of musk odors. Neuron. 2014;81(1):165-78. Epub 2013/12/24. doi: 10.1016/j.neuron.2013.10.021. PubMed PMID: 24361078.

26. Kuhlmann K, Tschapek A, Wiese H, Eisenacher M, Meyer HE, Hatt HH, Oeljeklaus S, Warscheid B. The membrane proteome of sensory cilia to the depth of olfactory receptors. Mol Cell Proteomics. 2014;13(7):1828-43. Epub 2014/04/22. doi: 10.1074/mcp.M113.035378. PubMed PMID: 24748648; PMCID: PMC4083118.

27. Liu J, Hürlimann V, Emter R, Natsch A, Esposito C, Linker SM, Zou Y, Zhou L, Wang Q, Riniker S, Kraft P. A New Family of Rigid Dienone Musks Challenges the Perceptive Range of the Human Olfactory Receptor OR5AN1. Synlett. 2020;31(10):972-6. doi: 10.1055/s-0040-1708009.

28. Tan CM, Brady AE, Nickols HH, Wang Q, Limbird LE. MEMBRANE TRAFFICKING OF G PROTEINCOUPLED RECEPTORS. Annu Rev Pharmacol. 2004;44(1):559-609. doi:

10.1146/annurev.pharmtox.44.101802.121558 PMID - 14744258.

29. Bush CF, Hall RA. Olfactory receptor trafficking to the plasma membrane. Cell Mol Life Sci. 2008;65(15):2289-95. doi: 10.1007/s00018-008-8028-z PMID - 18373063.

30. Peterlin Z, Firestein S, Rogers ME. The state of the art of odorant receptor deorphanization: a report from the orphanage. J Gen Physiol. 2014;143(5):527-42. Epub 2014/04/16. doi: 10.1085/jgp.201311151. PubMed PMID: 24733839; PMCID: PMC4003190.

31. Shepard BD, Natarajan N, Protzko RJ, Acres OW, Pluznick JL. A cleavable N-terminal signal peptide promotes widespread olfactory receptor surface expression in HEK293T cells. PLoS One. 2013;8(7):e68758. Epub 2013/07/11. doi: 10.1371/journal.pone.0068758. PubMed PMID: 23840901; PMCID: PMC3698168. 
32. Foster SR, Hauser AS, Vedel L, Strachan RT, Huang X-P, Gavin AC, Shah SD, Nayak AP, HaugaardKedström LM, Penn RB, Roth BL, Bräuner-Osborne H, Gloriam DE. Discovery of Human Signaling Systems: Pairing Peptides to G Protein-Coupled Receptors. Cell. 2019;179(4):895-908.e21. doi: 10.1016/j.cell.2019.10.010 PMID - 31675498.

33. Saito H, Kubota M, Roberts RW, Chi Q, Matsunami H. RTP family members induce functional expression of mammalian odorant receptors. Cell. 2004;119(5):679-91. Epub 2004/11/20. doi: 10.1016/j.cell.2004.11.021. PubMed PMID: 15550249.

34. Bubnell J, Jamet S, Tomoiaga D, D'Hulst C, Krampis K, Feinstein P. In Vitro Mutational and Bioinformatics Analysis of the M71 Odorant Receptor and Its Superfamily. PLoS One. 2015;10(10):e0141712. Epub 2015/10/30. doi: 10.1371/journal.pone.0141712. PubMed PMID: 26513476; PMCID: PMC4626375.

35. Feinstein P, Bozza T, Rodriguez I, Vassalli A, Mombaerts P. Axon guidance of mouse olfactory sensory neurons by odorant receptors and the beta2 adrenergic receptor. Cell. 2004;117(6):833-46. Epub 2004/06/10. doi: 10.1016/j.cell.2004.05.013. PubMed PMID: 15186782.

36. Ross EM. G Protein-coupled receptors: Multi-turnover GDP/GTP exchange catalysis on heterotrimeric G proteins. Cell Logist. 2014;4:e29391. Epub 2014/10/04. doi: 10.4161/cl.29391. PubMed PMID: 25279250; PMCID: PMC4160333.

37. Edelstein SJ, Le Novere N. Cooperativity of allosteric receptors. J Mol Biol. 2013;425(9):1424-32. Epub 2013/03/26. doi: 10.1016/j.jmb.2013.03.011. PubMed PMID: 23523898.

38. Keshelava A, Solis GP, Hersch M, Koval A, Kryuchkov M, Bergmann S, Katanaev VL. High capacity in G protein-coupled receptor signaling. Nat Commun. 2018;9(1):876. Epub 2018/03/02. doi: 10.1038/s41467-01802868-y. PubMed PMID: 29491460; PMCID: PMC5830429.

39. Makhlouf M, D’Hulst, C. , Omura, M., Mina, R., Bernal-Garcia, S., Rosa, R., Saraiva, L.R., and Feinstein, P. Common Odorant Receptor Choice Mechanisms Revealed by Analysis of a Highly Represented Odorant Receptor Transgene. bioRxiv. 2021.

40. McClintock TS, Khan N, Xie C, Martens JR. Maturation of the Olfactory Sensory Neuron and Its Cilia. Chem Senses. 2020;45(9):805-22. Epub 2020/10/20. doi: 10.1093/chemse/bjaa070. PubMed PMID: 33075817; PMCID: PMC8133333.

41. Trivedi DK, Sinclair E, Xu Y, Sarkar D, Walton-Doyle C, Liscio C, Banks P, Milne J, Silverdale M, Kunath T, Goodacre R, Barran P. Discovery of Volatile Biomarkers of Parkinson's Disease from Sebum. Acs Central Sci. 2019;5(4):599-606. doi: 10.1021/acscentsci.8b00879.

Acknowledgments: We are grateful to Givaudan for providing musk compounds. We thank the Hunter College Animal Facility Manager Barbara Wolin and Veterinarian Patricia Glennon for help in maintaining the transgenic colony, and Rada Norinsky and her team of the Transgenic Core Facility at The Rockefeller University for generating transgenic founders. We would like to thank Rosco Technologies/Dr. Dmitry Rinberg for setting up of headspace odor delivery system. Many thanks to Viktoriya Syrovatkina for critical organizational aspects of the project and Nicole Zeak for Technical support. We thank the rest of the Yesse Technologies team: Elke Giets, Christophe Lemetre, Eugene Lempert, Raena Mina, Yumi Fujisawa, Luis Hoffman, Chloe Vermierre and Thomas Pauwelyn for their thoughtful contributions to the platform development. A special thanks to Thomas Bozza for review and insightful comments on the manuscript.

\section{Funding: NSF SBIR Phase II Award: 1720679; NSF SBIR Phase II Award: 1853051.}

Author contributions: M.O. and P.F. designed constructs and animal analysis experiments; M.O. performed construct cloning and analyzed transgenic animals; Y.T. and S.B. performed QC for ex vivo bioassay; Y.T. and M.O. designed, performed and analyzed bioassay experiments; Y.T, M.O. and P.F. prepared figures; M.O., P.F., Y.T., C.D., and S.B. wrote the manuscript.

Competing interests: Previously awarded patent that relates to work: W02017024028A1. 
bioRxiv preprint doi: https://doi.org/10.1101/2021.09.28.462154; this version posted September 30, 2021. The copyright holder for this preprint (which was not certified by peer review) is the author/funder. All rights reserved. No reuse allowed without permission.

Data and materials availability: If data are in an archive, include the accession number. Mice and Cilia Extracts require an MTA. 


\section{Figure Legends:}

Transgenic Expression of Any Odorant Receptor and Isolation of Olfactory Cilia

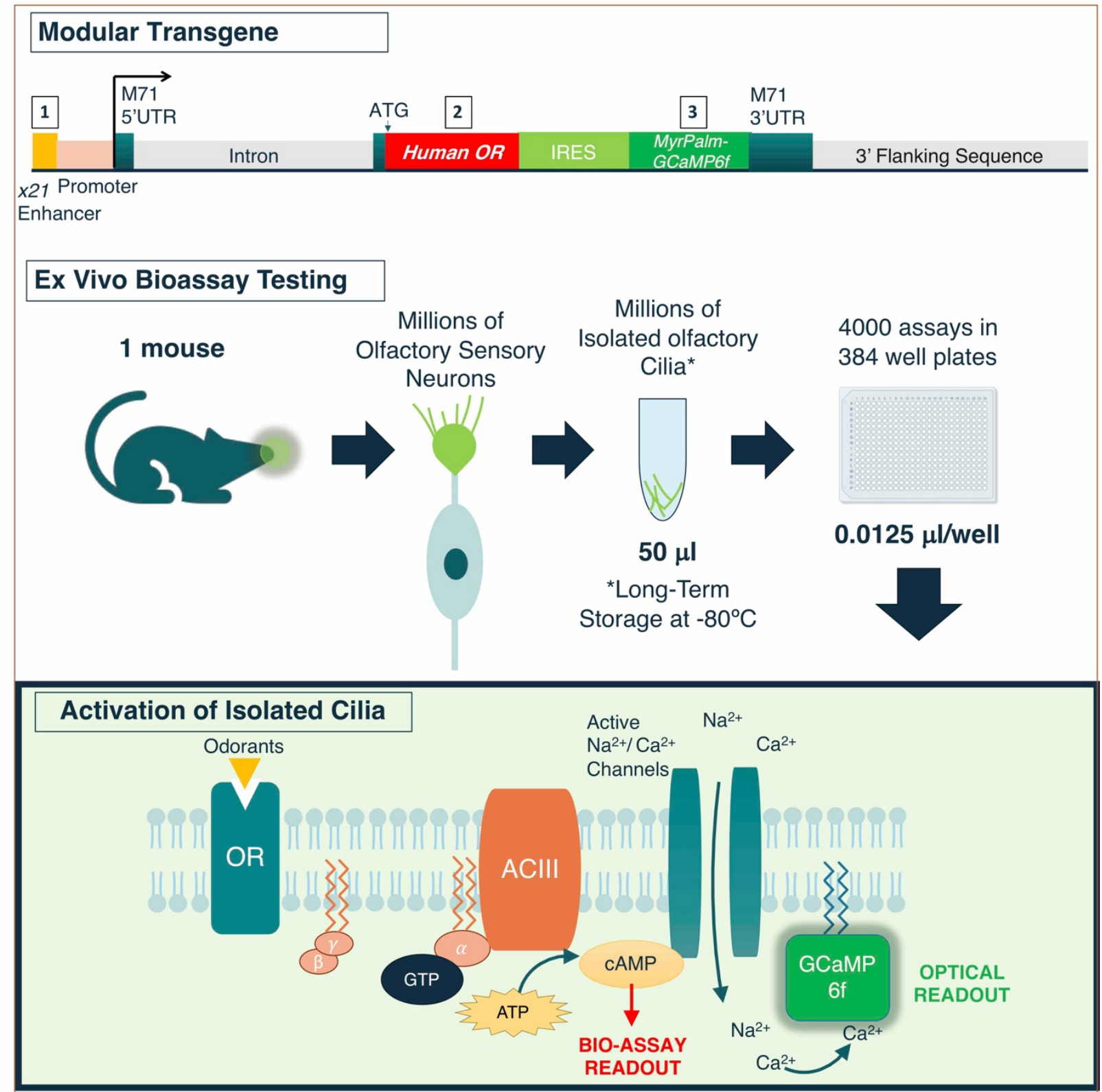

Fig. 1. Ex vivo platform pipeline. Human ORs are expressed using a modular transgenic construct. A high probability gene choice enhancer (from $5 \times 21$ or $9 \times 21$ ) sequence allows for the selective expression of the human OR together with a membrane targeted fluorescent reporter such as IRES MyrPalm-GCaMP6f. Transgenic mice express the OR and reporter in their olfactory epithelium, in which the olfactory cilia are extracted for use in an ex vivo bioassay. A biochemical assay measures cyclic AMP accumulation while a fluorescent readout measuring calcium influx is also possible. 


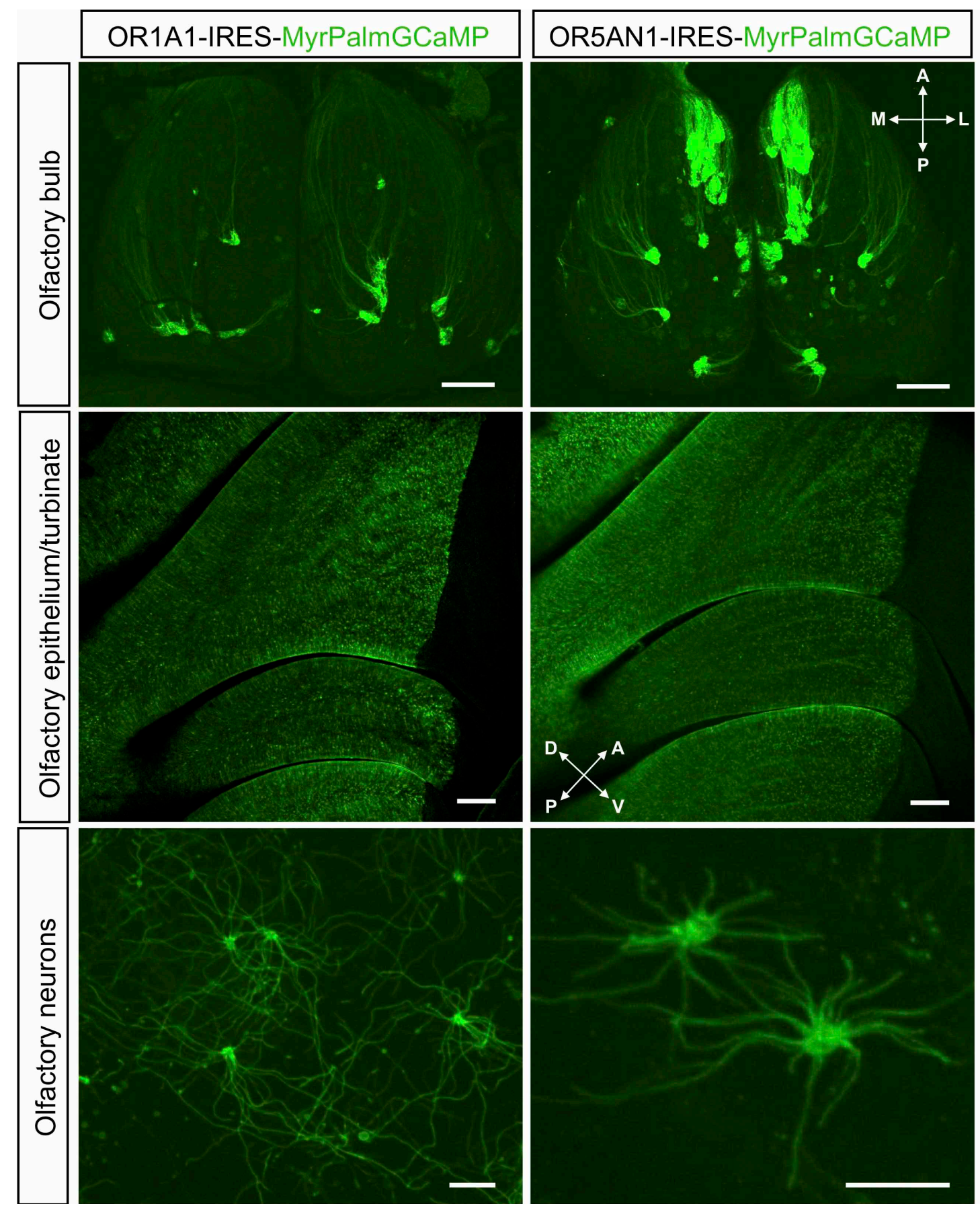

Fig. 2. Myrpalm-GCaMP6f expressions in OR1A1 and OR5AN1 transgenic animals.

The upper panels show the dorsal view of the olfactory bulbs of OR1A1-IRES-MyrpalmGCaMP6f transgenic animals (left), and OR5AN1-IRES-Myrpalm-GCaMP6f (right), scalebar $500 \mu \mathrm{m}$. The middle panels show medial wholemount views of the main olfactory epithelium and turbinates of OR1A1 (left) and OR5AN1 (right), scalebar 200 $\mu \mathrm{m}$. The bottom panels show high magnification en face view of the GCaMP positive olfactory sensory neurons of OR1A1 and OR5AN1animals, left and right respectively. A, anterior; P, posterior; L, lateral; and M, medial; D, dorsal; V, ventral, scale bars $10 \mu \mathrm{m}$. 
A

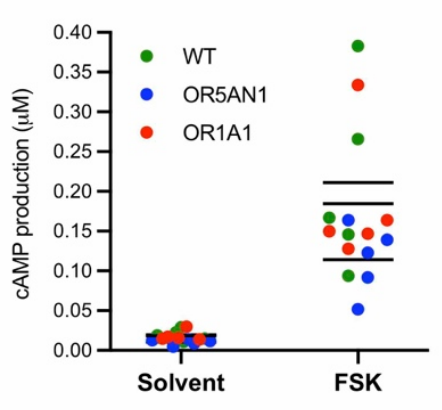

B

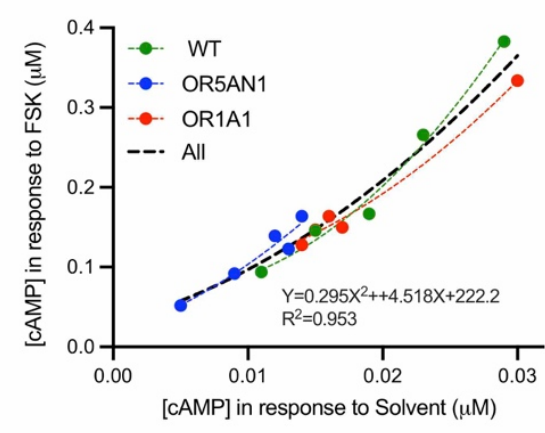

C

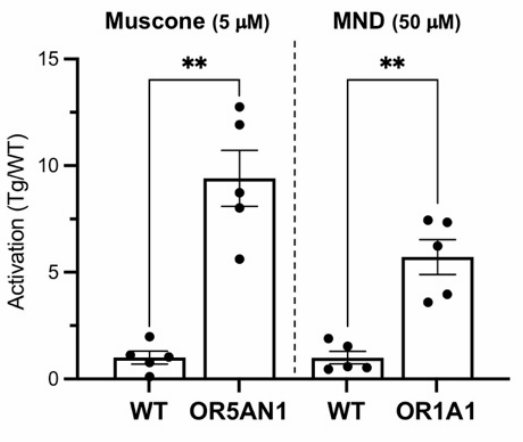

Fig. 3. Ex vivo activation of human ORs with ligands. (A) Activation of wild type control (WT), OR5AN1 and OR1A1 hOR bioextracts with $5 \mu \mathrm{M}$ forskolin (FSK), and the solvent, the bars represent mean and dots show datapoint of produced cAMP bars represent mean and dots show data points of produced cAMP by solvent and FSK, All groups are $\mathrm{N}=5$ biological replicates. (B) Correlation between cAMP in response to FSK (vertical axis) versus to solvent (horizontal axis). The dots show data points from 5 biological replicates with best fit nonlinear regression curves. (C) Activation of WT and OR5AN1 hOR bioextracts with $5 \mu \mathrm{M}$ muscone, $\mathrm{N}=5$ biological replicates, and activation of WT and OR1A1 hOR bioextracts with $50 \mu \mathrm{M}$ 3-methyl-2,4-nonanedione (MND), data represents activation values: [(odor-DMSO)/DMSO $]^{\mathrm{Tg} /}\left[\left(\right.\right.$ odor-DMSO)/DMSO ${ }^{\mathrm{WT}}$ with \pm $\mathrm{SEM}$, superimposed data points, $\mathrm{N}=5$ biological replicates. Mann-Whitney test, $* * \mathrm{p}<0.01$. 

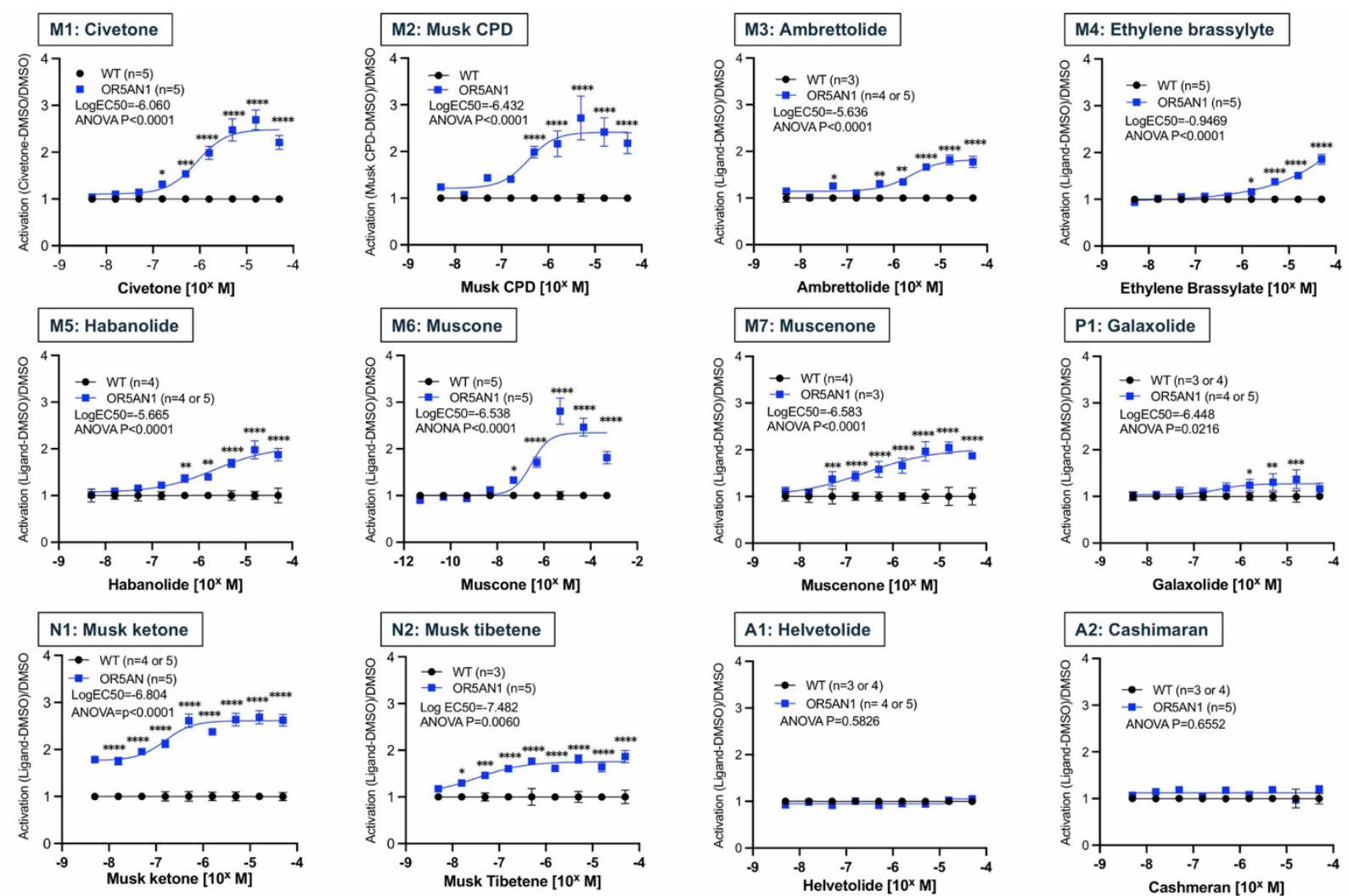

Fig. 4. Ex vivo activation of OR5AN1 with 12 musk compounds. Activation of wild type control (WT) and OR5AN1 hOR bioextracts using a nine-point log dilution curve of 12 musk compounds, the black circles and blue squares, WT and OR5AN1 respectively, show mean of activation value corrected with its WT value \pm SEM. $N=3-5$ biological replicates as indicated in each graph. EC50 was calculated from the best fit nonlinear regression curve (four parameters) with the corrected activation values. Two-way ANOVA was performed, and p-values of the interaction were as indicated. Fisher's LSD test was applied as post hoc comparisons, ${ }^{*} \mathrm{p}<0.05, * * \mathrm{p}<0.01, * * * \mathrm{p}<0.001$, $* * * * \mathrm{p}<0.0001$. 
A

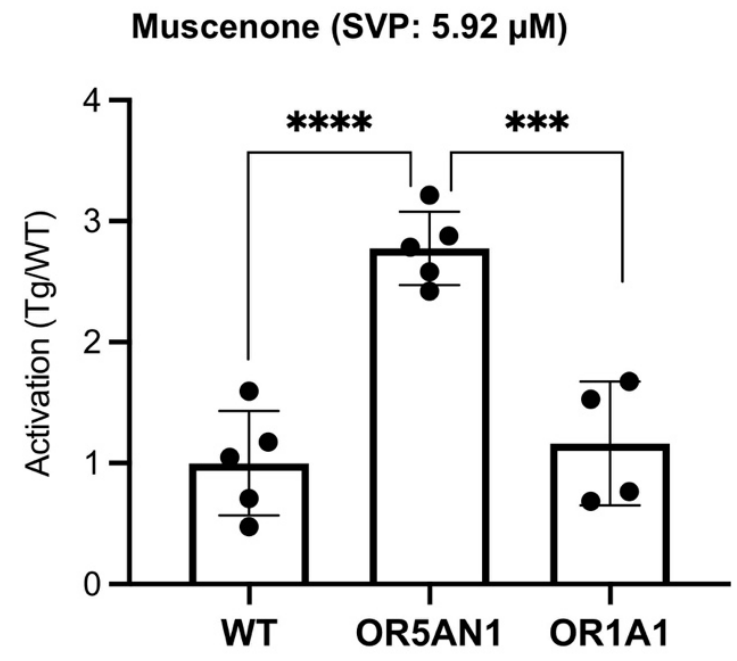

B

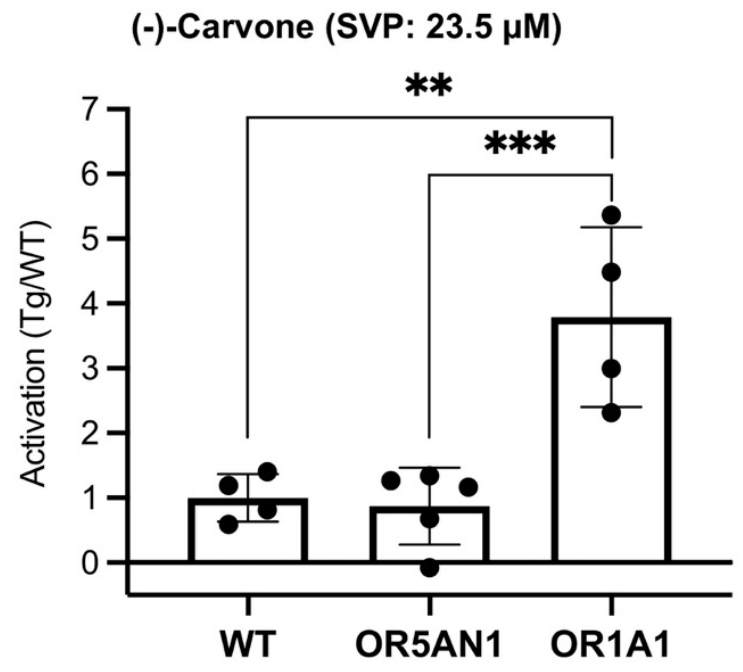

Fig. 5. Headspace odor activation of OR1A1 and OR5AN1. (A) Activation of wild type control (WT), OR1A1 and OR5AN1 hOR bioextract using a vapor-phase delivery of Muscenone at saturated vapor pressure (SVP) concentration, $5.92 \mu \mathrm{M}$. WT; $\mathrm{N}=5$, OR5AN1; N=5, OR1A1; N=4 biological replicates, error bars show SEM. Ordinary Oneway ANOVA with Fisher's LSD test for each pair compared, ***p $<0.001$, $* * * * \mathrm{p}<0.0001$. (B) Activation of WT, OR1A1 and OR5AN1 hOR bioextract using a vapor-phase delivery of (-)-carvone at SVP concentration, $23.5 \mu \mathrm{M}$. WT; N=4, OR5AN1; $\mathrm{N}=5$, OR1A1; $\mathrm{N}=4$ biological replicates, error bars show SEM. Ordinary One-way ANOVA with Fisher's LSD test for each pair compared, $* * p<0.01, * * * p<0.001$. 


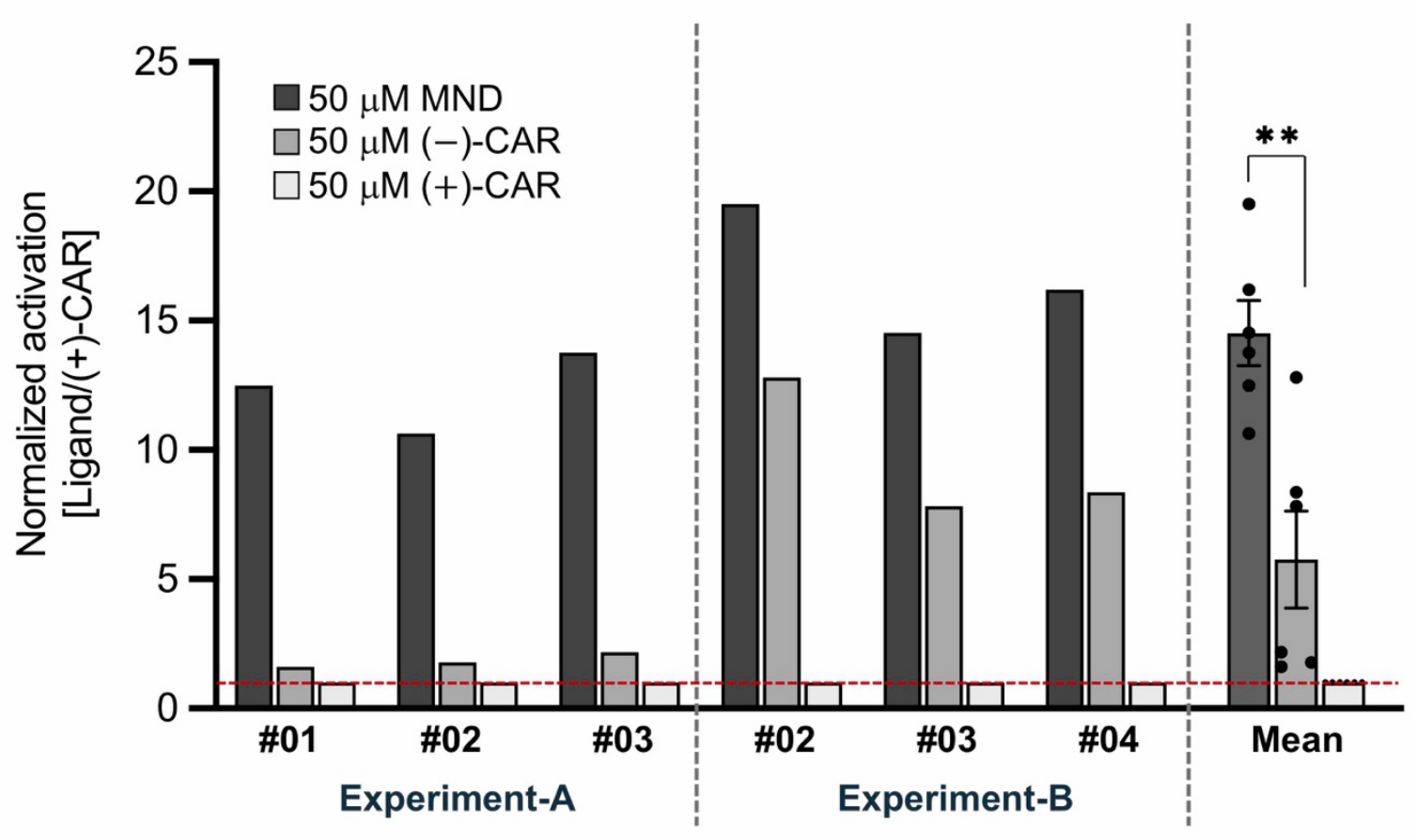

Fig. 6. Comparison of ex vivo activation of OR1A1 with three known ligands. Activation of OR1A1 bioextracts with 3-methyl-2,4-nonanedione (MND), (-)-carvone [(-)-CAR], and $(+)$-carvone $[(+)-\mathrm{CAR}]$. The activation value: [(odor-DMSO)/DMSO $]^{\mathrm{Tg}} /$ [(odor- $^{-}$ $\mathrm{DMSO}) / \mathrm{DMSO}]^{\mathrm{WT}}$ of the three ligands were normalized with the value of $(+)-\mathrm{CAR}$. The red dash line shows one. Six data points from two independent assays (Experiment \#A and $\#$ B). The right three columns show mean of the six OR1A1 data points represented as dots with SEM. Mann-Whitney test for normalized MND activation and (-)-CAR, $* * \mathrm{p}=0.0087$. 


\section{Supplementary Materials}

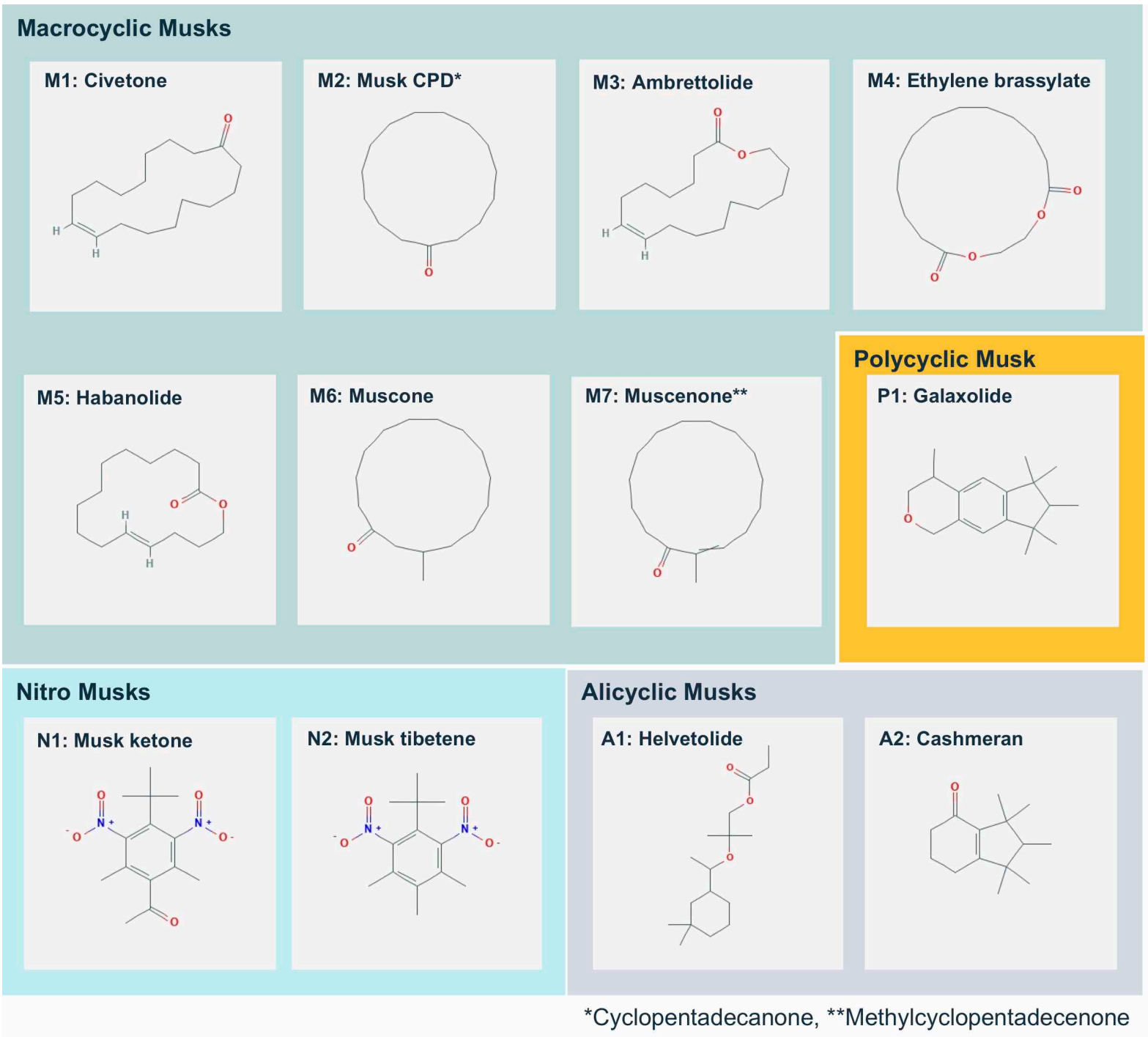

Fig. S1. Structure of 12 Musks used for activation of OR5AN1. M=Macrocyclic musks, $\mathrm{N}=$ Nitro-musk derivatives, $\mathrm{P}=$ Polycyclic musks, $\mathrm{A}=$ Alicyclic musks 
Activation values: (Ligand-DMSO)/DMSO
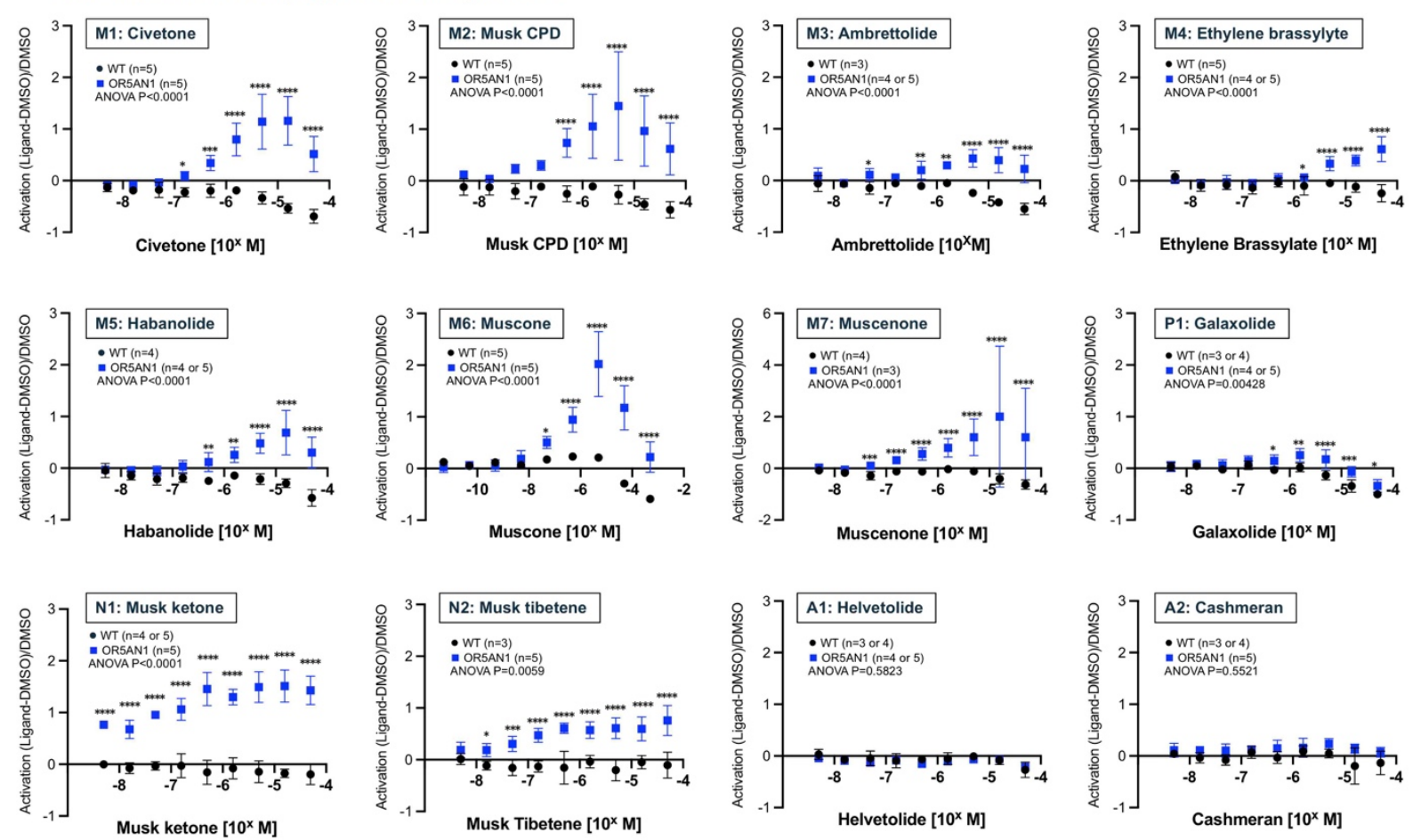

Fig. S2. Ex vivo activation of OR5AN1 with 12 musk compounds. Activation of wild type control (WT) and OR5AN1 hOR bioextracts using a nine-point log dilution curve of 12 musk compounds, the black circles and blue squares, WT and OR5AN1 respectively, show mean of activation values: [(odor-DMSO)/DMSO] with $\pm \mathrm{SD} n=3-5$ biological replicates as indicated in each graph. Two-way ANOVA was performed, and p-value was as indicated. Fisher's LSD test was applied as post hoc comparisons, ${ }^{*} \mathrm{p}<0.05,{ }^{*} \mathrm{p}<0.01$, $* * * p<0.001, * * * * p<0.0001$. 
Activation values normalized by WT : [(Ligand-DMSO)/DMSO $]^{\mathrm{Tg}}$ / [(Ligand-DMSO)/DMSO ${ }^{\mathrm{WT}}$
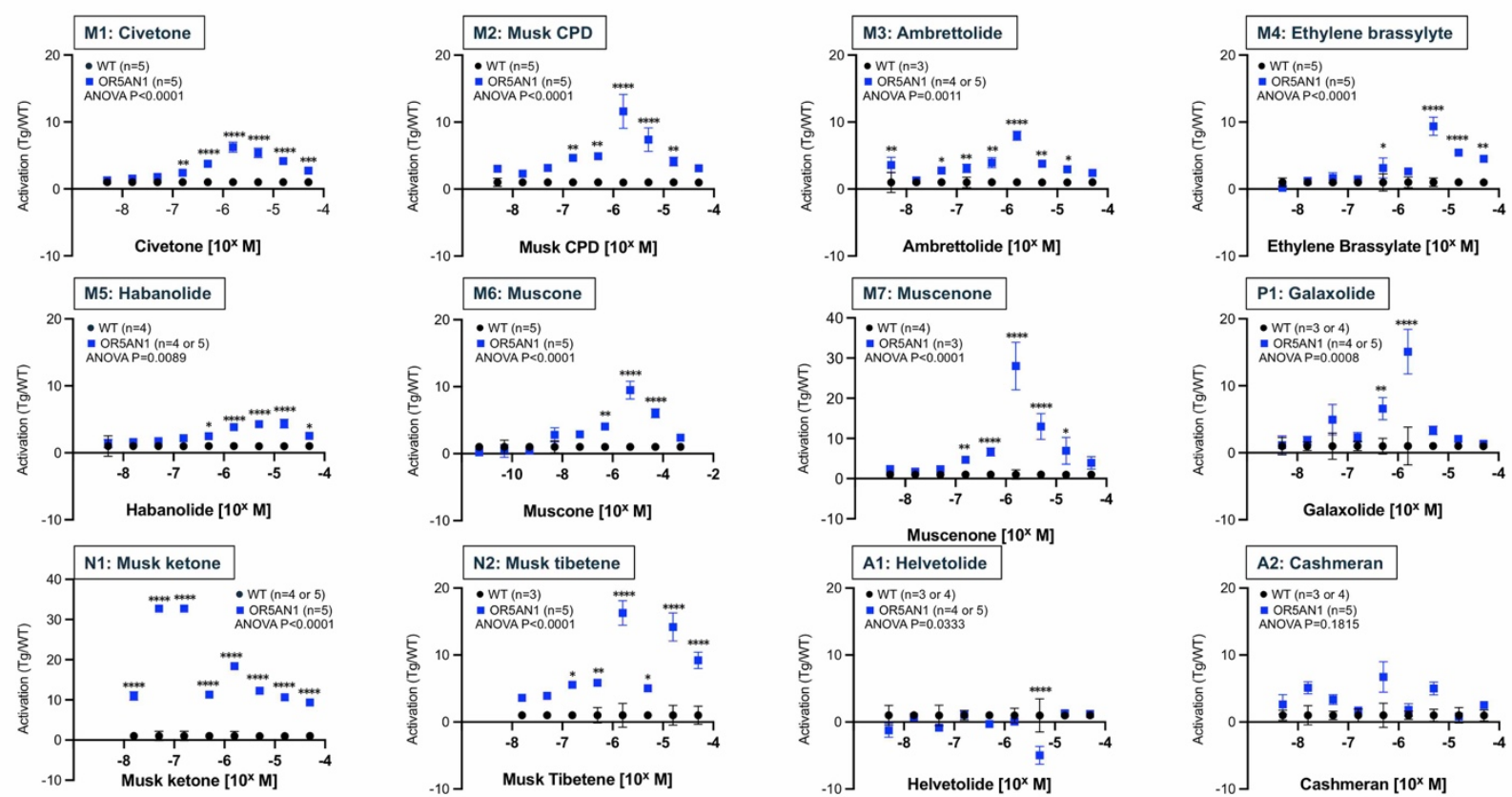

Fig. S3. Normalization of ex vivo activation of OR5AN1 with 12 musk compounds. Activation of wild type control (WT) and OR5AN1 hOR bioextracts using a nine-point log dilution series of 12 musk compounds, the black circles and blue squares, WT and OR5AN1 respectively, show mean of normalized activation values (OR5AN1 activation values were normalized with its WT): [(odor-DMSO)/DMSO $]^{\mathrm{Tg}} /[($ odor$\mathrm{DMSO}) / \mathrm{DMSO}]^{\mathrm{WT}}$ with $\pm \mathrm{SEM}, \mathrm{N}=3 \sim 5$ biological replicates as indicated in each graph. Two-way ANOVA was performed, and p-value was as indicated. Fisher's LSD test as post hoc comparisons, ${ }^{*} \mathrm{p}<0.05,{ }^{*} \mathrm{p}<0.01,{ }^{*} * \mathrm{p}<0.001, * * * * \mathrm{p}<0.0001$. 
A

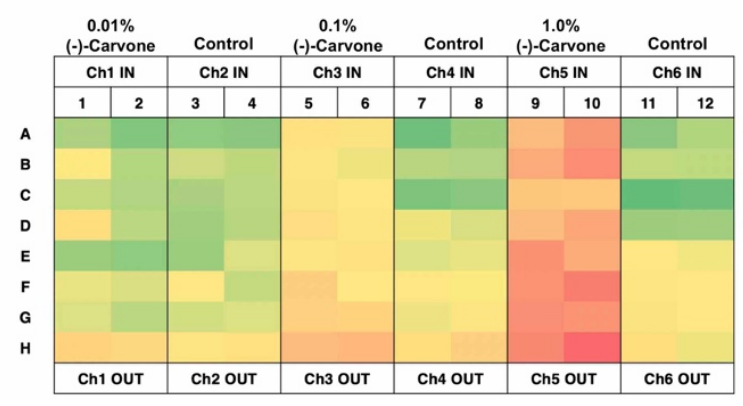

B

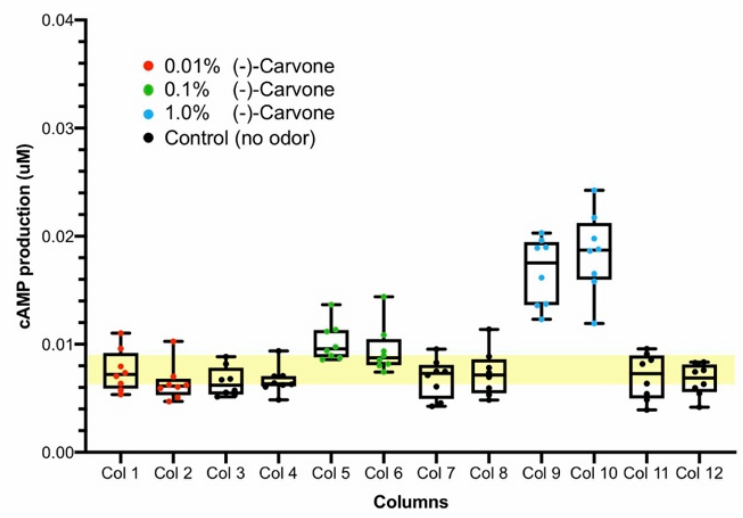

Fig. S4. Vapor phase odor delivery system and ex vivo activation of OR1A1 with vapor phase delivered (-)-carvone. Our vapor phase odor delivery system has 6 independent channels to deliver odors to two columns (16 wells) in a 96-well plate at the same time. (A) A heatmap of the activation of bioextract of OR1A1 with a series of dilution of (-)carvone in 96 well plate layout. The level of cAMP production from the wells is shown in green to red color indicator. Diluted (-)-carvones, $0.01 \%, 0.1 \%$ and $1.0 \%$ were delivered from channel 1 (Ch1 IN), channel 3 (Ch3 IN), channel 5 (Ch6 IN), respectively. Channel 2, 4, 6 (Ch2 IN, Ch4 IN and Ch6 IN) were control (unopened). (B) A nested box plot of cAMP production in OR1A1 bioextract with vapor phase (-)-carvones delivery is shown in (A). Each box show means with minimum to max with SD. The yellow area indicates the mean $\pm \mathrm{SD}$ of 6 control columns ( $\mathrm{Col} 3,4,7,8,11$, and 12). 

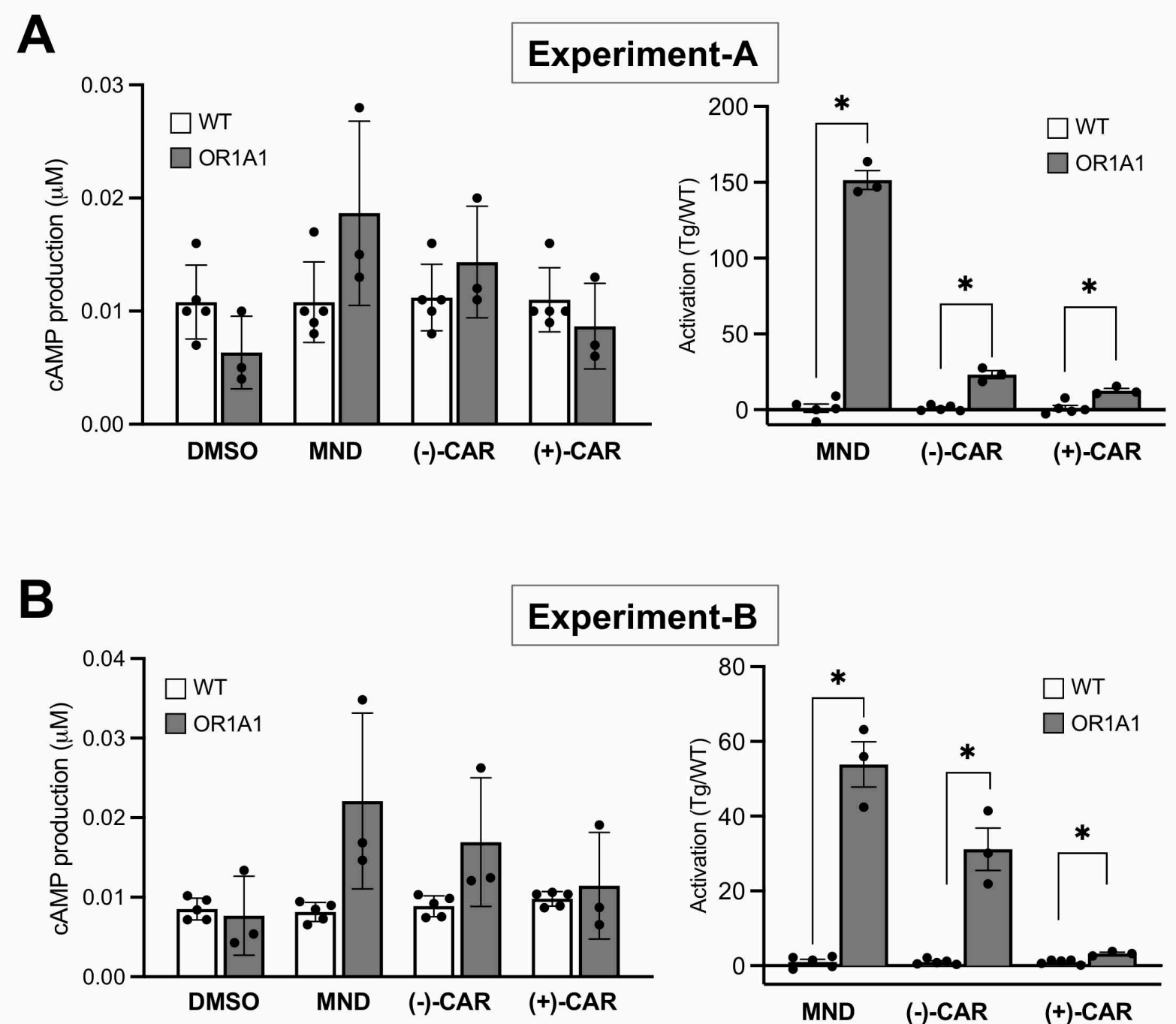

\section{ent-B}

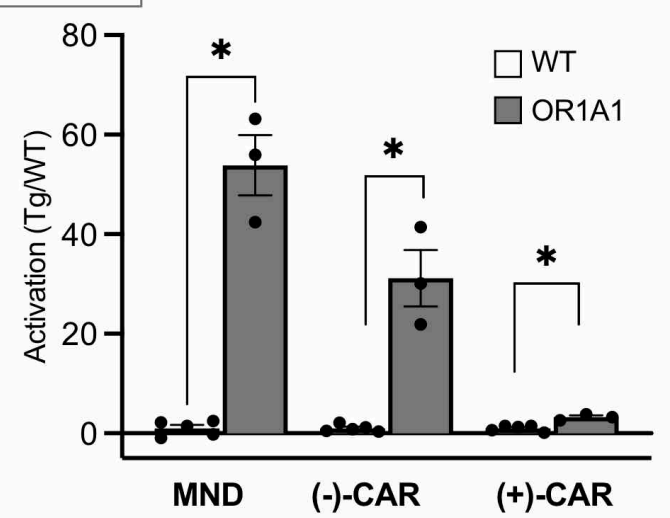

Fig. S5. Ex vivo activation of OR1A1 with three known ligands. Activation of OR1A1 bioextracts with $50 \mu \mathrm{M} 3$-methyl-2,4-nonanedione (MND), $50 \mu \mathrm{M}(-)$-carvone [(-)$\mathrm{CAR}]$, and $50 \mu \mathrm{M}(+)$-carvone $[(+)-\mathrm{CAR}]$ from two independent experiments. (A) The results from experiment $A$, the left panel shows the means of cAMP production in wild type control (WT) and OR1A1 bioextract with SD and superimposed data points, and the right panel shows means of the calculated activation value: [(odor-

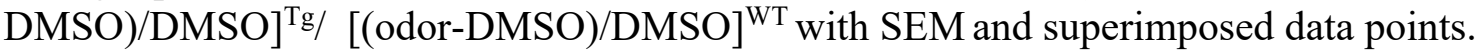
WT $n=5$, OR1A1 N=3. (B) The results from experiment $B$, the left panel shows the mean of cAMP production in WT and OR1A1 bioextract with SD and superimposed data points, and the right panel shows means of the calculated activation values with SEM. WT N=5, OR1A1 N=3. Mann-Whitney test, * $p<0.05$. 